\author{
Stanisław Wanat \\ Uniwersytet Ekonomiczny w Krakowie \\ e-mail: wanats@uek.krakow.pl
}

ORCID: 0000-0001-6225-4207

\title{
Krzysztof Guzik
}

Uniwersytet Ekonomiczny w Krakowie

e-mail: guzikk@uek.krakow.pl

ORCID: 0000-0002-5335-9450

ODPORNOŚĆ STANDARDOWEJ FORMUŁY WYZNACZANIA KAPITAŁOWYCH WYMOGÓW WYPLACALNOŚCI NA BLĘDNĄ SPECYFIKACJĘ ZALEŻNOŚCI*

\section{ROBUSTNESS OF THE STANDARD FORMULA FOR THE SOLVENCY CAPITAL REQUIREMENT CALCULATION FOR AN INCORRECT DEPENDENCY SPECIFICATION}

DOI: $10.15611 / \mathrm{pn} .2018 .541 .22$

JEL Classification: C150, C580, G220

Streszczenie: Tematyka referatu wpisuje się w dyskusję dotyczącą poprawności stosowanej w Solvency II standardowej formuły wyznaczania kapitałowych wymogów wypłacalności. Uwagę skoncentrowano na odporności tej formuły na błędną specyfikację struktury zależności. W pracy, wykorzystując jedno z najnowszych narzędzi szacowania ograniczeń dla VaR, pokazano na konkretnym przykładzie, że stosowanie formuły standardowej zgodnie z Rozporządzeniem Delegowanym Komisji (UE) 2015/35, zapisanym w art. 115, może prowadzić do wyznaczenia kapitałowych wymogów dla ryzyka składki i rezerw na niewłaściwym poziomie. Z przeprowadzonej analizy wynika, że poprawne oszacowanie SCR-ów zależy od poprawnej identyfikacji struktury zależności między zmiennymi losowymi modelującymi nieoczekiwane straty. Wykorzystanie w tym celu tylko współczynników korelacji liniowej może prowadzić do błędnych wyników, gdyż opisują one w sposób jednoznaczny tylko zależności liniowe. Ogólnie różne struktury zależności mogą charakteryzować się taką samą wartością tego współczynnika.

Słowa kluczowe: kapitałowy wymóg wypłacalności, szacowanie ograniczeń dla VaR, agregacja ryzyka, algorytm RA.

* Publikacja została sfinansowana ze środków przyznanych Wydziałowi Finansów i Prawa Uniwersytetu Ekonomicznego w Krakowie w ramach dotacji na utrzymanie potencjału badawczego. 
Summary: The article subject fits into the discussion on the correctness of the standard formula for determining capital solvency requirements applied in Solvency II. Attention was focused on the robustness of this formula for an incorrect dependency specification. In the paper by using one of the latest tools of estimating VaR bounds on a concrete example it was shown that applying the standard formula according to the Commission Delegated Regulation (EU) $2015 / 35$ provided in Article 115, may result in determining the solvency capital requirements for the non-life premium and reserve risk at an inappropriate level. The performed analysis shows that the proper estimation of SCRs depends on the correct identification of the dependence structure between the random variables modelling unexpected losses. When only Pearson correlation coefficients are used for this purpose it may lead to erroneous results, because they describe explicitly only linear dependencies. In a general case different dependence structures can be characterized by the same value of this coefficient.

Keywords: Solvency Capital Requirement, VaR bounds estimation, risk aggregation, RA algorithm.

\section{Wstęp}

W ostatnich trzech dekadach w bankach i towarzystwach ubezpieczeniowych do pomiaru ryzyka wykorzystywana jest głównie wartość zagrożona (Value-at-Risk, VaR). Miara ta stanowi podstawę podejmowania decyzji w zakresie ograniczania ekspozycji na ryzyko do akceptowalnego poziomu, w zależności od dostępnego kapitału ekonomicznego, jak również jest wykorzystywana do ustalania wysokości kapitałów regulacyjnych, mających gwarantować wypłacalność. Między innymi stosuje się ją w Solvency II w standardowej metodzie wyznaczania kapitałowych wymogów wypłacalności (Solvency Capital Requirements, SCR). Nic więc dziwnego, że w literaturze przedmiotu odbyły się i nadal są prowadzone szeroko zakrojone debaty na temat możliwości wykorzystania wartości zagrożonej i jej ograniczeń w procesie agregacji ryzyka i oceny efektu dywersyfikacji (zob. np. [Embrechts i in. 2014; Embrechts i in. 2015; Emmer i in. 2015]).

Tematyka artykułu wpisuje się w dyskusję dotyczącą szacowania VaR dla zagregowanego ryzyka w warunkach niepewnej struktury zależności, tj. VaR dla sumy zmiennych losowych o znanych rozkładach jednowymiarowych, ale nieznanej zależności między nimi. Rozszerza on dotychczasową literaturę przedmiotu w zakresie ilościowego, wielowymiarowego modelowania ryzyka $\mathrm{w}$ procesie wyznaczania SCR-ów. Artykuł z wykorzystaniem znanych w literaturze metod szacowania ograniczeń dla VaR pokazuje, że stosowanie formuły standardowej zgodnie z Rozporządzeniem Delegowanym Komisji (UE) 2015/35 zapisanym w art. 115, bez identyfikacji rzeczywistej struktury zależności, może prowadzić do błędnego oszacowania kapitałowych wymogów wypłacalności dla ryzyka składki i rezerw w ubezpieczeniach innych niż ubezpieczenia na życie, oraz wskazuje, jak duże mogą to być błędy. Według najlepszej wiedzy autorów wyniki tego typu badań nie były jeszcze prezentowane w literaturze. 
W tekście omówiono metody szacowania ograniczeń dla VaR, krótko przedstawiono stosowaną w Solvency II standardową metodę szacowania kapitałowych wymogów wypłacalności dla ryzyka składki i rezerw w ubezpieczeniach innych niż ubezpieczenia na życie, a także zaprezentowano założenia i wyniki przeprowadzonego badania symulacyjnego oraz sformułowano wnioski.

\section{Metody szacowania ograniczeń dla VaR - przegląd literatury}

Załóżmy, że znamy dystrybuanty $F_{1}, \ldots, F_{n}$ zmiennych losowych $L_{1}, \ldots, L_{n}$ (modelujących straty związane $\mathrm{z}$ indywidualnymi rodzajami ryzyka) o skończonych wartościach oczekiwanych i wariancjach. Dla zmiennej $L_{j}$, gdzie $\{j=1, \ldots, n\}$, przy ustalonym poziomie istotności $\alpha$ przyjmujemy definicję wartości zagrożonej (VaR):

$$
\operatorname{VaR}_{1-a}\left(L_{j}\right)=\inf \left\{x \in R: F_{j}(x) \geq 1-a\right\} .
$$

Kluczowym problemem do rozwiązania jest wyznaczenie wartości zagrożonej dla zmiennej losowej $L=L_{1}+\ldots+L_{n}$, która modeluje zagregowane ryzyko (stratę łączną). Rozkład zmiennej losowej $L$ oraz w konsekwencji wartość zagrożona $\operatorname{VaR}_{1-a}(L)$ zależą jedynie od struktury zależności wielowymiarowego wektora $\left(L_{1}, \ldots, L_{n}\right)$. W praktyce najczęściej struktura ta nie jest znana i nie można wyznaczyć $\operatorname{VaR}_{1-a}(L)$. W takich przypadkach pewnym rozwiązaniem proponowanym w literaturze przedmiotu jest podanie górnego (dolnego) ograniczenia dla tej miary.

Pierwsze wyniki w szacowaniu ograniczeń dla VaR w przypadku nieznanej struktury zależności dla dwóch zmiennych losowych przedstawiono w pracach [Makarov 1981; Frank i in. 1987; Rüschendorf 1982]. W ostatnich latach problem ten jest omawiany w pracach [Puccetti, Rüschendorf 2012a; 2012 b; 2014; Embrechts i in. 2013; Puccetti i in. 2013; Bernard i in. 2016; 2017], przy czym wyniki uzyskiwane dla trzech lub więcej zmiennych losowych wymagają dość mocnych założeń, takich jak np. identyczność rozkładów brzegowych z monotonicznymi funkcjami gęstości (zob. [Puccetti 2013; Puccetti, Rüschendorf 2013]). Badania nad możliwością osłabienia tych założeń doprowadziły do opracowania algorytmów numerycznych do wyznaczania dolnego i górnego ograniczenia VaR dla dowolnych i niekoniecznie identycznych rozkładów. Algorytmy te w pewnym sensie odnoszą się do koherentnej miary ryzyka, jaką jest TVaR (Tail Value at Risk), inaczej zwana ES (Expected Shortfall). Wartość zagrożona VaR taką miarą nie jest, gdyż nie spełnia warunku subaddytywności. Zanim przejdziemy do omówienia algorytmów szacujących wartość zagrożoną, przypomnimy definicję TVaR oraz oszacowania, jakie bezpośrednio z tej definicji możemy uzyskać bez dodatkowych założeń, jak również przy założeniu ograniczonej wariancji zmiennej $L$ modelującej zagregowane ryzyka $L_{i},\{j=1, \ldots, n\}$.

Dla zmiennej losowej $L$ wartość TVaR definiujemy następująco:

$$
\operatorname{TVaR}_{1-a}(L)=\frac{1}{\alpha} \int_{1-\alpha}^{1} \operatorname{VaR}_{q}(L) d q,
$$


co oznacza, że $T V a R_{1-a}(L)$ możemy interpretować jako wartość średnią strat, gdy straty te przy ustalonym poziomie istotności $\alpha$ przekroczą $V_{a} R_{1-a}(L)$. Bezpośrednio z definicji (1) i (2) wynika nierówność:

$$
\operatorname{VaR}_{1-a}(L) \leq E S_{1-\alpha}(L) .
$$

Ponadto definiujemy $\operatorname{LTVaR}_{1-a}(L)$ (Left Tail Value at Risk) jako średnią strat, w przypadku gdy straty te nie przekroczą wartości zagrożonej przy ustalonym poziomie istotności $\alpha$, tzn.:

$$
\operatorname{LTVaR}_{1-a}(L)=\frac{1}{1-\alpha} \int_{0}^{1-\alpha} \operatorname{VaR}_{q}(L) d q .
$$

Przyjmujemy również, że $L^{C}=\sum_{j=1}^{n} L_{j}^{C}$ oznacza sumę zmiennych losowych $L_{1}, \ldots, L_{n}$ przy założeniu, że są one współmonotoniczne. Na podstawie tych definicji i oznaczeń można udowodnić (zob. twierdzenie 1 [Bernard i in. 2017, s. 929]) poniższe oszacowanie:

$$
\begin{gathered}
\frac{\operatorname{VaR}_{1-\alpha}(L)}{C}=A:=\sum_{j=1}^{n} \operatorname{LTVaR}_{1-\alpha}\left(L_{j}\right)=\operatorname{LTVaR}_{1-\alpha}\left(L^{C}\right) \leq \\
\operatorname{VaR}_{1-\alpha}(L) \leq \\
\operatorname{TVaR}_{1-\alpha}\left(L^{C}\right)=\sum_{j=1}^{n} \operatorname{TVaR}_{1-\alpha}\left(L_{j}\right)=: B=\overline{\operatorname{VaR}_{1-\alpha}(L)},
\end{gathered}
$$

gdzie $\operatorname{VaR}_{1-a}(L), \overline{\operatorname{VaR}_{1-a}(L)}$ oznacza odpowiednio dolne i górne oszacowanie $\operatorname{VaR}_{1-a} \overline{(L) . ~ W}$ porównaniu z wynikami prac [Puccetti, Rüschendorf 2012a; 2014] i [Embrechts i in. 2013] powyższe oszacowanie VaR podano w formie jawnej. Można je bez dodatkowych założeń i w prosty sposób bezpośrednio wyznaczyć z rozkładów brzegowych, które nie muszą być identyczne.

Jeżeli jednak przyjmiemy założenie o ograniczoności wariancji $L$ (taką informacją często dysponujemy na podstawie analizy danych historycznych), wtedy ograniczenia wyznaczone na podstawie wzoru (5) możemy poprawić, stosując formułę (zob. twierdzenie 5 [Bernard i in. 2017, s. 935]):

$$
a:=\max \left(\mu-s \sqrt{\frac{q}{1-q}}, A\right) \leq \operatorname{VaR}_{1-q}(L) \leq \min \left(\mu+s \sqrt{\frac{1-q}{q}}, B\right)=: b,
$$

gdzie $\mu=A(1-q)+B q, \operatorname{var}(L) \leq s^{2}$ oraz $A$ i $B$ są określone jak w (5). Podane oszacowania VaR (5) i (6) zostaną wykorzystane w dalszej części pracy i porównane m.in. z oszacowaniami uzyskanymi za pomocą algorytmów numerycznych, które pokrótce omówimy. 


\section{Algorytmy numeryczne wykorzystywane do szacowania ograniczeń VaR}

Podstawowy algorytm do szacowania ograniczeń VaR zaproponowano w pracach [Puccetti, Rüschendorf 2012b] i [Embrechts i in. 2013]. Nazywany jest algorytmem RA (Rearrangement Algorithm) i pozwala wyznaczyć oszacowania dla VaR przy znanych, niekoniecznie identycznych, rozkładach brzegowych. Wykorzystuje się w nim pojęcie porządku wypukłego. Przy założeniu, że nie znamy struktury zależności między zmiennymi losowymi $L_{j}(j=1, \ldots n)$, za pomocą algorytmu konstruujemy taką zależność między nimi, która minimalizuje $L$ w sensie porządku wypukłego (kolejne iteracje algorytmu zmniejszają wariancję $L$, nie zmieniając przy tym rozkładów $L_{j}$ ani wartości oczekiwanej $L$ ). W ten sposób wariancja rozkładu warunkowego $L \mid L>$ $\operatorname{VaR}_{1-a}(L)$ zostaje zminimalizowana, co w rezultacie (jak dowodzą autorzy algoryt$\mathrm{mu}$ ) prowadzi do otrzymania górnego oszacowania wartości zagrożonej.

W dalszej części tekstu przedstawiamy ideę algorytmu RA oraz szczegółowo omawiamy jego przebieg. Przy ustalonej liczbie punktów dyskretyzacji $N$ z ogona rozkładu $[1-a, 1]$ dla każdej zmiennej losowej $L_{j}$ wyznaczamy $N$ realizacji tej zmiennej. Następnie dla każdej zmiennej losowej permutujemy otrzymane wartości tak, aby realizacje sumy tych zmiennych losowych $L \mathrm{w} N$ punktach były do siebie zbliżone - w ten sposób zbliżamy się do średniej wartości zmiennej $L$ w ogonie rozkładu. Innymi słowy: minimalizujemy wariancję rozkładu warunkowego.

W celu omówienia przebiegu algorytmu przyjmujemy, że wektory $\boldsymbol{a}, \boldsymbol{b} \in \mathbb{R}^{N}$ są przeciwnie uporządkowane, jeżeli dla wszystkich $1 \leq j, k \leq N$ zachodzi nierówność $\left(a_{j}-a_{k}\right)\left(b_{j}-b_{k}\right) \leq 0$ oraz dla macierzy $\boldsymbol{X}$ o wymiarze $N \times n$ definiujemy dwa operatory: $s(\boldsymbol{X})=\min _{1 \leq i \leq N} \sum_{j=1}^{n} x_{i j}$ oraz $t(\boldsymbol{X})=\max _{1 \leq i \leq N} \sum_{j=1}^{n} x_{i j}$. Zgodnie z algorytmem RA górne oszacowanie $\overline{\operatorname{VaR}_{1-a}(L)}$ wyznaczamy w następujący sposób (por. [Embrechts i in. 2013]):

1. Ustalamy liczbę naturalną $N$ i żądany poziom zbieżności $\varepsilon$.

2. Definiujemy macierze:

$\underline{\boldsymbol{X}}=\left(\underline{x}_{i j}\right)_{N \times n}$, gdzie $\underline{x}_{i j}=F_{j}^{-1}\left((1-\alpha)+\frac{\alpha(i-1)}{N}\right)$,

$\overline{\boldsymbol{X}}=\left(\bar{x}_{i j}\right)_{N \times n}$, gdzie $\bar{x}_{i j}=F_{j}^{-1}\left((1-\alpha)+\frac{\alpha i}{N}\right)$,

dla $1 \leq j \leq n$.

3. Permutujemy losowo elementy w każdej kolumnie $\underline{X}$ i $\bar{X}$.

4. Iteracyjnie przestawiamy elementy $j$-tej kolumny $(1 \leq j \leq n)$ macierzy $\underline{\boldsymbol{X}}$ tak, aby uzyskać uporządkowanie przeciwne do sumy pozostałych kolumn. Otrzymujemy w ten sposób macierz $\underline{\boldsymbol{Y}}$.

5. Krok 4 powtarzamy do momentu, w którym zostanie spełniona nierówność: $s(\underline{\boldsymbol{Y}})-s(\underline{\boldsymbol{X}})<\varepsilon$. W ten sposób znajdujemy macierz $\underline{\boldsymbol{X}}^{*}$.

6. Stosując kolejno krok 4 i krok 5 dla macierzy $\overline{\boldsymbol{X}}$, znajdujemy macierz $\overline{\boldsymbol{X}^{*}}$.

7. Definiujemy $\underline{s}_{N}=s\left(\underline{\boldsymbol{X}}^{*}\right)$ oraz $\bar{s}_{N}=s\left(\boldsymbol{X}^{*}\right)$. 
Otrzymany w ten sposób przedział $\left(\underline{s}_{N}, \bar{s}_{N}\right)$ zawiera $\overline{V a R_{1-a}(L)}$, a ponadto jego średnica dla odpowiednio dużego $N$ zmierza do 0 . Okazuje się jednak, że zbieżność $\left|\overline{s_{N}}-\underline{s_{N}}\right| \rightarrow 0$ może nie zachodzić. Wynika to z faktu, że w algorytmie za pomocą $\varepsilon$ badana jest „indywidualna zbieżność” $\bar{S}_{N}$ oraz $\underline{s}_{N}$. Może się więc zdarzyć, że te wartości nie będą wystarczająco bliskie siebie, aby oszacowanie $\overline{\operatorname{VaR}_{1-a}(L)}$ było na rozsądnym poziomie. W celu zminimalizowania ryzyka takiego przypadku należy dokonać losowej permutacji w kolumnach wejściowych macierzy $\underline{\boldsymbol{X}}$ i $\overline{\boldsymbol{X}}$ (krok 3 algorytmu). Analogicznie (za pomocą $t(X)$ ) wyznaczamy $\operatorname{VaR}_{1-a}(L)$.

Niestety wydajność algorytmu RA ulega znacznemu pogorszeniu wraz ze wzrostem liczby agregowanych zmiennych $L_{j}$. Na przykład przy założeniu, że ich liczba wynosi $10(n=10)$, a punktów dyskretyzacji jest $20(N=20)$, mamy do analizy około $2 \cdot 10^{165}$ macierzy wymiaru $20 \times 10$. Dodatkowym problemem przy zastosowaniu algorytmu RA jest ustalenie na rozsądnym poziomie wartości $N$ oraz $\varepsilon$ (autorzy algorytmu RA nie skupiają się na tym problemie).

W pracy [Hofert i in. 2017] na przykładzie rozkładu Pareto (z różnymi wartościami parametru $\theta$ ) zbadano działanie algorytmu RA pod kątem różnej liczby punktów dyskretyzacji $N$ oraz przy różnej liczbie zmiennych $n$. Rezultatem tych analiz było zaproponowanie algorytmu ARA (Adaptive Rearrangement Algorithm). Jego przebieg jest analogiczny do przebiegu algorytmu RA, przy następujących modyfikacjach:

- Liczba punktów dyskretyzacji wynosi $N=2^{k}$, przy czym autorzy (na podstawie symulacji) zalecają, aby $k \in\{8,9, \ldots 19\}$ oraz $k$ było wybierane w zależności od stopnia zbieżności. Maksymalna liczba kolumn poddawanych przegrupowaniu nie powinna przekraczać $10 n$.

- Poziom zbieżności jest badany za pomocą wektora $\varepsilon=\left(\varepsilon_{1}, \varepsilon_{2}\right)$, gdzie $\varepsilon_{1}$ jest tolerancją relatywnej zbieżności odpowiednio dolnego i górnego ograniczenia $\overline{\operatorname{VaR}_{1-a}}(L)$, czyli $\overline{s_{N}}$ oraz $s_{N}$, natomiast $\varepsilon_{2}$ jest tolerancją relatywnej zbieżności łącznej, przy czym: $\frac{s(\underline{\underline{Y}})-s(\underline{\boldsymbol{X}})}{s(\underline{\boldsymbol{X}})}<\varepsilon_{1}, \frac{s(\bar{Y})-s(\bar{X})}{s(\bar{X})}<\varepsilon_{1}$, oraz $\frac{\left(\bar{s}_{N}-\underline{s}_{N}\right)}{\bar{s}_{N}}<\varepsilon_{2}$.

- W algorytmie ARA zbieżność łączna jest badana po przegrupowaniu każdej kolumny. Wartością poziomu tolerancji $\varepsilon$ proponowaną przez autorów jest $\varepsilon=0,0.01)$, jakkolwiek w algorytmie można ją ustalić dowolnie.

Widać zatem, że algorytm ARA jest tylko zmodyfikowaną wersją RA. Jednak dzięki tym modyfikacjom zdecydowanie szybciej znajduje on optymalne oszacowanie. W części empirycznej niniejszego opracowania zastosowano algorytm ARA, przyjmując $N=256$.

Przeprowadzone symulacje numeryczne wskazują na wysoką precyzję algorytmów RA i ARA. Efektem ich zastosowania jest uzyskanie oszacowania górnej i dolnej granicy VaR. Jednak otrzymany przedział, jak wskazują liczne przykłady, jest dość szeroki. Wynika to z faktu nieuwzględnienia żadnej informacji o strukturze zależności między zmiennymi losowymi brzegowymi. W związku tym Bernard 
i współpracownicy w pracy [Bernard $\mathrm{i}$ in. 2017] zaproponowali algorytm ERA (Extended Rearrangement Algorithm), za pomocą którego szacowali ograniczenia VaR dla $L$ przy znanych rozkładach brzegowych $F_{j}$ i dodatkowo przy założeniu ograniczonej wariancji rozkładu łącznego $\operatorname{var}(L) \leq s^{2}$. Jak można się spodziewać, założenie o ograniczonej wariancji poprawia oszacowania otrzymane za pomocą algorytmów RA i ARA. Ideą algorytmu ERA jest wyznaczenie minimalnego elementu sumy $L \mathrm{w}$ sensie porządku wypukłego dla górnej i dolnej części rozkładu $L$ podzielonego (dla ustalonego $k$ i $N$ punktów dyskretyzacji) przez poziom ufności $1-\alpha=\frac{k}{N}$ oraz przy spełnieniu założenia o ograniczonej wariancji. W tym celu, analogicznie jak

w RA, należy dokonać przegrupowań kolumn w macierzach wyznaczonych odpowiednio dla dolnej i górnej części rozkładu $L$. Algorytm ERA wykorzystuje przy tym ograniczenia podane wzorami (5) i (6).

\section{Standardowa metoda szacowania SCR dla ryzyka składki i rezerw w ubezpieczeniach innych niż na życie}

W standardowym podejściu Solvency II całkowity kapitałowy wymóg wypłacalności (Overall Solvency Capital Requirement) dla ubezpieczyciela wyliczany jest z wykorzystaniem następującej formuły ${ }^{1}$ :

$$
S C R=B S C R+A d j+S C R_{O p},
$$

gdzie: $B S C R$ - podstawowy kapitałowy wymóg wypłacalności, $A d j$ - dostosowania z tytułu zdolności rezerw techniczno-ubezpieczeniowych i podatków odroczonych do pokrywania strat, $S C R_{O p}$ - wymóg kapitałowy dla ryzyka operacyjnego. Wartość $B S C R$ ustalana jest w procesie agregacji SCR-ów wyznaczonych dla głównych modułów ryzyka (tj. ryzyka ubezpieczeniowego: w ubezpieczeniach innych niż na życie, w ubezpieczeniach na życie i w ubezpieczeniach zdrowotnych oraz ryzyka rynkowego i ryzyka niewykonania zobowiązania przez kontrahenta), SCR-y dla modułów wyznaczane są na drodze agregacji SCR-ów dla podmodułów, a z kolei te ostatnie w wyniku agregacji SCR-ów dla nośników ryzyka². Zatem proces ten obejmuje 3 poziomy agregacji, są one szczegółowo przedstawione m.in. w [Commission Delegated... 2015, rozdz. V] i [Wanat 2014a; 2014 b]. Kapitałowe wymogi wypłacalności dla każdego ryzyka (tj. modułu, podmodułu, nośnika) na danym poziomie agregacji powinny odpowiadać kapitałowi ekonomicznemu $(E C)$ wyznaczonemu dla jednego roku, na poziomie ufności 0,995 [Dyrektywa Parlamentu Europejskiego... 2009, nota 64 , s. 7].

\footnotetext{
1 Zobacz [Dyrektywa Parlamentu Europejskiego... 2009, art. 103].

2 Sposób wyznaczania wartości $A d j$ i $S C R_{O p}$ jest przedstawiony w [QIS5 Technical ... 2010].
} 
Zatem zgodnie z definicją $E C$ (por. np. [Lelyveld 2006]) powinny być równe:

$$
\operatorname{SCR}_{i}^{(l)}=\operatorname{VaR}_{0.995}\left(L_{i}^{(l)}\right), \quad L_{i}^{(l)}=X_{i}^{(l)}-E\left(X_{i}^{(l)}\right),
$$

gdzie $X_{i}^{(l)}$ oznacza zmienną losową opisującą straty w rocznym horyzoncie czasowym związane $i$-tym ryzykiem na $l$-tym poziomie agregacji (zatem $L_{i}^{(l)}$ oznacza nieoczekiwane straty dla tego ryzyka).

W dalszej części pracy uwagę koncentrujemy na podmodule ryzyka składki i rezerw w ubezpieczeniach innych niż na życie ${ }^{3}$. Formuła standardowa na SCR dla tego podmodułu jest następująca (zob. [Commission Delegated... 2015, art. 15]):

$$
S C R_{n l \text { prem res }}=3 \cdot \sigma_{n l} \cdot V_{n l},
$$

gdzie: $\sigma_{n l}$ - odchylenie standardowe ryzyka składki i rezerw w ubezpieczeniach innych niż na życie wyznaczone zgodnie z art. 117 [Commission Delegated... 2015]; $V_{n l}$ - miara wielkości ryzyka składki i rezerw w ubezpieczeniach innych niż na życie, wyznaczone zgodnie z art. 116 [Commission Delegated... 2015]. Przy tym $V_{n l}$ jest równe:

$$
V_{n l}=\sum_{s} V_{s}
$$

gdzie $V_{s}$ oznacza miarę wielkości ryzyka składki i rezerw dla segmentu $s$ (wykaz segmentów podano w Annex II [Commission Delegated... 2015]).

Kluczową rolę w oszacowaniu SCR na podstawie wzoru (9) odgrywa odchylenie standardowe $\sigma_{n l}$, które jest wyznaczane następująco (zob. [Commission Delegated... 2015, art. 117, par. 1]):

$$
\sigma_{n l}=\frac{1}{V_{n l}} \cdot \sqrt{\sum_{s, t} \operatorname{Corr}_{s, t} \cdot \sigma_{s} \cdot V_{s} \cdot \sigma_{t} \cdot V_{t}},
$$

gdzie: $\operatorname{Corr} S_{s, t}$ - parametr zależności ryzyka składki i rezerw w ubezpieczeniach innych niż na życie dla segmentów $s$ i $t$ określony w Annex IV [Commission Delegated... 2015]; $\sigma_{s}, \sigma_{t}$ - odchylenia standardowe ryzyka składki i rezerw w ubezpieczeniach innych niż na życie odpowiednio dla segmentów $s$ i $t ; V_{s}, V_{t}-$ miara wielkości ryzyka składki i rezerw odpowiednio dla segmentów $s$ i $t$, o których mowa w art. 116 [Commission Delegated... 2015]. Odchylenie standardowe ryzyka składki i rezerw dla konkretnego segmentu $s$ jest równe (zob. [Commission Delegated... 2015, art. 117, par. 2]):

$$
\sigma_{s}=\frac{\sqrt{\sigma_{(p r, s)}^{2} \cdot V_{(p r, s)}^{2}+\sigma_{(p r, s)} \cdot V_{(p r, s)} \cdot \sigma_{(r e s, s)} \cdot V_{(r e s, s)}+\sigma_{(r e s, s)}^{2} \cdot V_{(r e s, s)}^{2}},}{V_{(p r, s)}+V_{(r e s, s)}}
$$

${ }^{3}$ W wyniku agregacji SCR dla tego podmodułu z SCR dla podmodułu ryzyka katastroficznego i podmodułu ryzyka związanego z rezygnacjami otrzymuje się SCR dla modułu ryzyka aktuarialnego w ubezpieczeniach innych niż na życie. Jest to drugi poziom agregacji. 
gdzie: $\sigma_{(p r s)}$ - odchylenie standardowe ryzyka składki dla segmentu $s$ wyznaczone zgodnie z art. 117, par. 3 [Commission Delegated... 2015]); $\sigma_{(r e s, s)}-$ odchylenie standardowe ryzyka rezerw dla segmentu $s$ określone w Annex II [Commission Delegated... 2015]; $V_{(p, s)}, V_{(r e s, s)}$ - odpowiednio miara wielkości ryzyka składki i ryzyka rezerw dla segmentu $s$, o której mowa w art. 116 [Commission Delegated... 2015].

$\mathrm{Z}$ tego wynika, że w standardowej formule na $S C R_{\text {nl prem res }}$ nie zakłada się explicite postaci rozkładu zmiennej modelującej nieoczekiwane straty. W dalszym ciągu tę zmienną będziemy oznaczać przez $L_{n l}$ (w celu zachowania przejrzystości zapisu pomijamy superskrypt oznaczający poziom agregacji). Biorąc jednak pod uwagę ogólną zasadę mówiącą, że SCR dla danego ryzyka powinien zabezpieczać nieoczekiwane straty na poziomie ufności 0,995 (por. wzór (8)) oraz postać wzoru (9), można stwierdzić, że takie założenie jest potrzebne. Mianowicie dla rozkładu normalnego: $\operatorname{VaR}_{0,995}(X)=c \cdot \sigma_{X}$, gdzie $c=\Phi^{-1}(0,995)=2,58$. W formule standardowej stała $c=3$. Oznacza to, że SCR jest szacowany na poziomie ufności 0,9987 , zatem wyższym niż ogólnie przyjęty. Ma to, zdaniem ustawodawców, zapobiec niedoszacowaniu SCR, gdy $L_{n l}$ nie ma rozkładu normalnego.

Kolejna wątpliwość związana ze stosowaniem formuły standardowej na

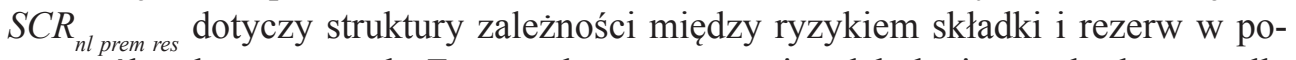
szczególnych segmentach. Ze sposobu wyznaczania odchylenia standardowego dla zagregowanego ryzyka składki i rezerw (wzór (11)) wynika, że jest ona opisywana tylko za pomocą współczynników korelacji liniowej. Ponieważ takie same współczynniki korelacji mogą odpowiadać różnym strukturom zależności, powstaje oczywiste pytanie: w jakim stopniu szacowany w ten sposób SCR jest wiarygodny? Ile może różnić się od SCR-u oszacowanego przy uwzględnieniu prawidłowej struktury zależności? W celu odpowiedzi na te pytania dla konkretnego przypadku przeprowadzono badanie, którego wyniki zaprezentowano w następnym punkcie.

\section{SCR dla ryzyka skladki i rezerw - wyniki empiryczne}

W punkcie tym przedstawiono wyniki badania, w którym analizowano wrażliwość SCR dla ryzyka składki i rezerw dwóch segmentów ubezpieczeń innych niż na życie na strukturę zależności między tymi segmentami. Rozważane segmenty to:

- ubezpieczenia odpowiedzialności cywilnej z tytułu użytkowania pojazdów mechanicznych i reasekuracja proporcjonalna (segment $s$ ),

- pozostałe ubezpieczenia pojazdów i reasekuracja proporcjonalna (segment $t$ ).

Dla rozważanych segmentów założono takie same wartości miary wielkości ryzyka, natomiast wartości niezbędnych odchyleń standardowych i parametru korelacji przyjęto jak w Annex II i Annex IV [Commission Delegated... 2015] (patrz tab. 1). 
Tabela 1. Założenia analizy empirycznej

\begin{tabular}{|c|c|}
\hline Segment $s$ & Segment $t$ \\
\hline$V_{(\text {prem }, s)}=1,0$ & $\mathrm{~V}_{(\text {prem }, t)}=1,0$ \\
\hline$V_{(\text {res }, s)}=1,2$ & $V_{(\text {res }, t)}=1,2$ \\
\hline$\sigma_{(\text {prem }, s)}=0,10$ & $\sigma_{(\text {prem }, t)}=0,08$ \\
\hline$\sigma_{(\text {res }, s)}=0,09$ & $\sigma_{(\text {res }, t)}=0,08$ \\
\hline & \\
\hline
\end{tabular}

Źródło: obliczenia własne.

Następnie zgodnie ze standardową formułą (por. wzór (9)) obliczono SCR, uzyskując wartość $S C R_{\text {nl prem res }}=0,8656$ (por. tab. 2). Z kolei założono, że zmienne losowe $L_{s}, L_{p}$, które modelują nieoczekiwane straty dla ryzyka składki i rezerw odpowiednio segmentu $s$ i $t$, mają rozkłady normalne: $L_{s} \sim N\left(0, V_{s} \cdot \sigma_{s}\right), L_{p} \sim N\left(0, V_{p} \cdot \sigma_{p}\right)$. Dla przyjętych parametrów (tab. 1) otrzymano (po dokonaniu niezbędnych obliczeń z zastosowaniem m.in. wzoru (12)): $L_{s} \sim N(0,0.1802), L_{p} \sim N(0,0.1526)$. Przy tych założeniach, wykorzystując formułę (8) dla zmiennej $L_{n l}=L_{s+} L_{p}$, wyznaczono SCR dla następujących przypadków:

- A: zmienne $L_{s}$ i $L_{p}$ są niezależne.

- B: zmienne $L_{s}^{s}$ i $L_{p}^{p}$ są współmonotoniczne.

- C: nieznana struktura zależności między $L_{s}$ i $L_{p}$. Górne ograniczenie SCR wyznaczono, wykorzystując TVAR, zgodnie z formułą (5).

- D: nieznana struktura zależności między $L_{s}$ i $L_{p}$. Górne ograniczenie SCR wyznaczono, wykorzystując algorytm ARA.

- E: częściowo znana struktura zależności, tzn. wiadomo tylko, że współczynnik korelacji między $L_{s}$ i $L_{p}$ wynosi 0,5 (por. tab. 1). Górne ograniczenie SCR wyznaczono na podstawie (6).

Uzyskane wyniki przedstawiono w tab. 2.

Tabela 2. Wyniki analizy empirycznej

\begin{tabular}{|c|c|}
\hline Przypadek & Wymogi kapitałowe \\
\hline Solvency II standard formula & 0,8656 \\
\hline A & 0,6060 \\
\hline B & 0,8573 \\
\hline C & $\left(0,6060^{*}, 0,9625\right)$ \\
\hline D & $\left(0,6060^{*}, 0,9342\right)$ \\
\hline E & $\left(0,6060^{*}, 0,9251\right)$ \\
\hline
\end{tabular}

* Przyjęto najniższy SCR dla niezależnych zmiennych losowych $L_{s}$ i $L_{p}$.

Źródło: obliczenia własne.

Na podstawie przeprowadzonego badania można wyciągnąć następujące wnioski:

- W procesie wyznaczania kapitałowych wymogów wypłacalności dla ryzyka składki i rezerw w ubezpieczeniach innych niż na życie znajomość tylko rozkła- 
dów zmiennych losowych $L_{s}$ i $L_{p}$ bez wiedzy o strukturze zależności między nimi jest niewystarczająca. Otrzymany w takim przypadku przedział możliwych wartości dla SCR od ${ }^{4}$ 0,6060 do 0,9342 (przypadek D) z praktycznego punktu widzenia jest bezużyteczny.

- Wykorzystanie do opisu struktury zależności tylko współczynnika korelacji (jak to ma miejsce w standardowej formule Solvency II) jest niewystraczające. Taki sam współczynnik korelacji między $L_{s}$ i $L_{p}$ może bowiem odpowiadać różnym strukturom zależności, a zatem różnym wartościom SCR. W przeprowadzonym badaniu (przypadek E) górne ograniczenie dla SCR uzyskano na poziomie 0,9251. Oznacza to, że SCR może być wyższy od wyznaczonego za pomocą formuły standardowej o $6,9 \%$.

- Za pomocą formuły standardowej otrzymano SCR wyższy niż przy założeniu współmonotonicznej struktury zależności między $L_{s}$ i $L_{p}$ (przypadek B), czyli wyższy od sumy SCR-ów dla segmentów $s$ i $t$. Oznacza to, że stosując formułę standardową na SCR, w rozważanym przypadku nieuwzględniany jest efekt dywersyfikacji.

\section{Podsumowanie}

W pracy pokazano na konkretnym przykładzie, że stosowanie formuły standardowej zgodnie z Rozporządzeniem Delegowanym Komisji (UE) 2015/35 zapisanym w art. 115 może prowadzić do wyznaczenia kapitałowych wymogów wypłacalności dla ryzyka składki i rezerw w ubezpieczeniach innych niż na życie na niewłaściwym poziomie. Z przeprowadzonej analizy wynika, że poprawne oszacowanie SCR zależy od poprawnej identyfikacji struktury zależności między zmiennymi losowymi modelującymi nieoczekiwane straty. Wykorzystanie w tym celu tylko współczynników korelacji liniowej może prowadzić do błędnych wyników, gdyż opisują one w sposób jednoznaczny tylko zależności liniowe. Ogólnie różne struktury zależności mogą charakteryzować się taką samą wartością tego współczynnika. W pracy założono rozkład normalny dla nieoczekiwanych strat. W praktyce jednak bardzo często są to rozkłady asymetryczne. Kolejnym etapem prowadzonych badań będzie analiza efektu skośności w procesie szacowania kapitałowych wymogów wypłacalności.

\section{Literatura}

Bernard C., Denuit M., Vanduffel S., 2016, Measuring portfolio risk under partial dependence information, Journal of Risk and Insurance (w druku).

Bernard C., Rüschendorf L., Vanduffel S., 2017, Value-at-Risk bounds with variance constraints, Journal of Risk and Insurance, 84(3), s. 923-959.

\footnotetext{
${ }^{4}$ Za najniższą wartość przyjęto SCR dla niezależnych zmiennych $L_{s}$ i $L_{p}$.
} 
Commission Delegated Regulation (EU) 2015/35 of 10 October 2014 supplementing Directive 2009/138/EC of the European Parliament and of the Council on the taking-up and pursuit of the business of Insurance and Reinsurance (Solvency II), Official Journal of the European Union, 17.1.2015.

Dyrektywa Parlamentu Europejskiego i Rady Europy 2009/138/WE z dnia 25 listopada 2009 r.

Embrechts P., Puccetti G., Rüschendorf L., 2013, Model uncertainty and VaR aggregation, Journal of Banking \& Finance, 37(8), s. 2750-2764.

Embrechts P., Puccetti G., Rüschendorf L., Wang R., Beleraj A., 2014, An academic response to Basel 3.5, Risks, 2(1), s. 25-48.

Embrechts P., Wang B., Wang R., 2015, Aggregation-robustness and model uncertainty of regulatory risk measures, Finance and Stochastics, 19(4), s. 763-790.

Emmer S., Kratz M., Tasche D., 2015, What is the best risk measure in practice? A comparison of standard measures, Journal of Risk 18(2), s. 31-60.

Frank M.J., Nelsen R.B., Schweizer B., 1987, Best-possible bounds for the distribution of a sum - a problem of Kolmogorov, Probability Theory and Related Fields, vol. 74(2), s. 199-211.

Hofert M., Memartoluie A., Saunders D., Wirjanto T., 2017, Improved algorithms for computing worst Value-at-Risk, Statistics \& Risk Modeling, 34(1-2), s. 13-31.

Lelyveld I. V., 2006, Economic capital modelling: Concepts, measurement and implementation, Risk Books, London.

Makarov G.D., 1981, Estimates for the distribution function of the sum of two random variables when the marginal distributions are fixed, Theory of Probability \& its Applications, 26(4), s. 803-806.

Puccetti G., 2013, Sharp bounds on the expected shortfall for a sum of dependent random variables, Statistics \& Probability Letters, 83(4), s. 1227-1232.

Puccetti G., Rüschendorf L., 2012a, Bounds for joint portfolios of dependent risks, Statistics \& Risk Modeling, 29(2), s. 107-132.

Puccetti G., Rüschendorf L., 2012b, Computation of sharp bounds on the distribution of a function of dependent risks, Journal of Computational and Applied Mathematics, 236(7), s. 1833-1840.

Puccetti G., Rüschendorf L., 2013, Sharp bounds for sums of dependent risks, Journal of Applied Probability, 50(1), s. 42-53.

Puccetti G., \& Rüschendorf L., 2014, Asymptotic equivalence of conservative value-at-risk and expected shortfall-based capital charges, The Journal of Risk, 16(3), s. 3-22.

Puccetti G., Wang B., Wang R., 2013, Complete mixability and asymptotic equivalence of worst-possible VaR and ES estimates, Insurance: Mathematics and Economics, 53(3), s. 821-828.

QIS5 Technical Specifications - European Commission, 2010, Retrieved February 24, 2017, https:/ eiopa.europa.eu/publications/qis/insurance/insurance-quantitative-impact-study-5/technical-specifications

Rüschendorf L., 1982, Random variables with maximum sums, Advances in Applied Probability, vol. 14(3), s. 623-632.

Wanat S., 2014a, Efekt dywersyfikacji ryzyka w Solvency II w świetle wyników ilościowego badania wptywu QIS5, Prace Naukowe Uniwersytetu Ekonomicznego we Wrocławiu, nr 371, s. 320-330.

Wanat S., 2014b, Ocena efektu dywersyfikacji ryzyka w Solvency II - aspekt praktyczny i metodologiczny, Wiadomości Ubezpieczeniowe, nr (3), s. 31-48. 